\title{
EL RETORNO DE LOS INVASORES
}

\author{
The Return of Egon Wolff's Invaders
}

\section{RESUMEN}

Estigmatizadas como crítica del resentimiento, las humanidades profetizaron la Revolución de Octubre (Chile, 19 oct. 2019). Contra el denuesto, aquí se reclama que una de las profecías más agudas, la ofrecerían la producción dramática y teatral, y los saberes que convergen en torno a sus historias y críticas. De manera ejemplar, se ofrece una lectura cronística de Los invasores (1963), de Egon Wolff (1926-2016). A través de ella, se describen aspectos cardinales de esta coyuntura imprevista por medios de comunicación y think tanks hegemónicos: el retorno intempestivo del pueblo, la denuncia de un Estado-nación que deviene zona de sacrificio y la urgencia de refundar los códigos - métricos y lingüísticos - en que se cifran los contratos sociales legados por la doctrina shock dictatorial.

Palabras claves: revolución de octubre (Chile); performance; dramaturgia chilena; Egon Wolff; Los Invasores.

\section{UNIVERSUM}

Revista de Humanidades y Ciencias Sociales

\section{CRISTIÁN OPAZO}

Doctor en Literatura, Pontificia Universidad Católica de Chile.

Correo electrónico:

cmopazo@uc.cl

ORCID: 0000-0002-9951-9309 ResearchGate: Cristian_Opazo5 Scholar.google:

Academia.edu: CristiánOpazo

Artículo recibido el 3 de marzo, 2020. Aceptado el 4 de junio, 2020.

DOI:

Web: http://universum.utalca.cl | ISSN: 0716-498X - 0718-2376 


\begin{abstract}
Disdained as School of Resentment, humanities prophesied the October Revolution (Chile, 19 Oct. 2019). Against insults, in this essay, I insist that theatre and performance-the critical and historiographical traditions involved in its study-have portrayed one of the most accurate prophecies of the present. To demonstrate my statement, I will offer a close reading of The Invaders [Los invasores] (1963), by Egon Wolff (1926-2016). Through this critical exercise, I'll finally describe the cornerstones of this social crisis. From the perspective of neoliberal think tanks and hegemonic mass media, this is yet an unpredictable event. Naturally, I'm referring to (a) the return of the people [pueblo], (b) the denounce uttered by these people about a Nation-state that became a sacrifice zone, and (c) the urgent need-also diagnosticated by the same people - of refunding the cultural codes bequeathed by the shock doctrine installed under the dictatorship.
\end{abstract}

Keywords: October Revolution (Chile); performance; Chilean dramaturgy; Egon Wolff; Los Invasores [The Invaders].

\title{
ESCUELA DEL RESENTIMIENTO
}

Tal como si se tratara de las esculturas de los próceres de la Conquista, nuestra Revolución de Octubre (18 oct. 2019) arrancó de sus pedestales a los intelectuales orgánicos canonizados por los medios de comunicación hegemónicos $\mathrm{y}$, sobre todo, por los think tanks que, bajo la doctrina del shock, arrebatan el protagonismo a las universidades complejas en el diseño y la discusión de las leyes de la República (Fig. 1). ${ }^{1}$ Efectivamente, hasta la

1 El autor es investigador adscrito al Núcleo Milenio Arte, Performatividad y Activismo, N Mapa (http://nmapa.cl), proyecto financiado por la Iniciativa Científica Milenio (ICM), del Ministerio de Ciencia, Tecnología, Innovación y Conocimiento, del Gobierno de Chile. Este trabajo forma parte de proyecto Fondecyt Regular 1201369, "Comunidades de la Violencia", del que es investigador responsable.

Es ampliamente sabido que en su imprescindible La doctrina del shock: el auge del 


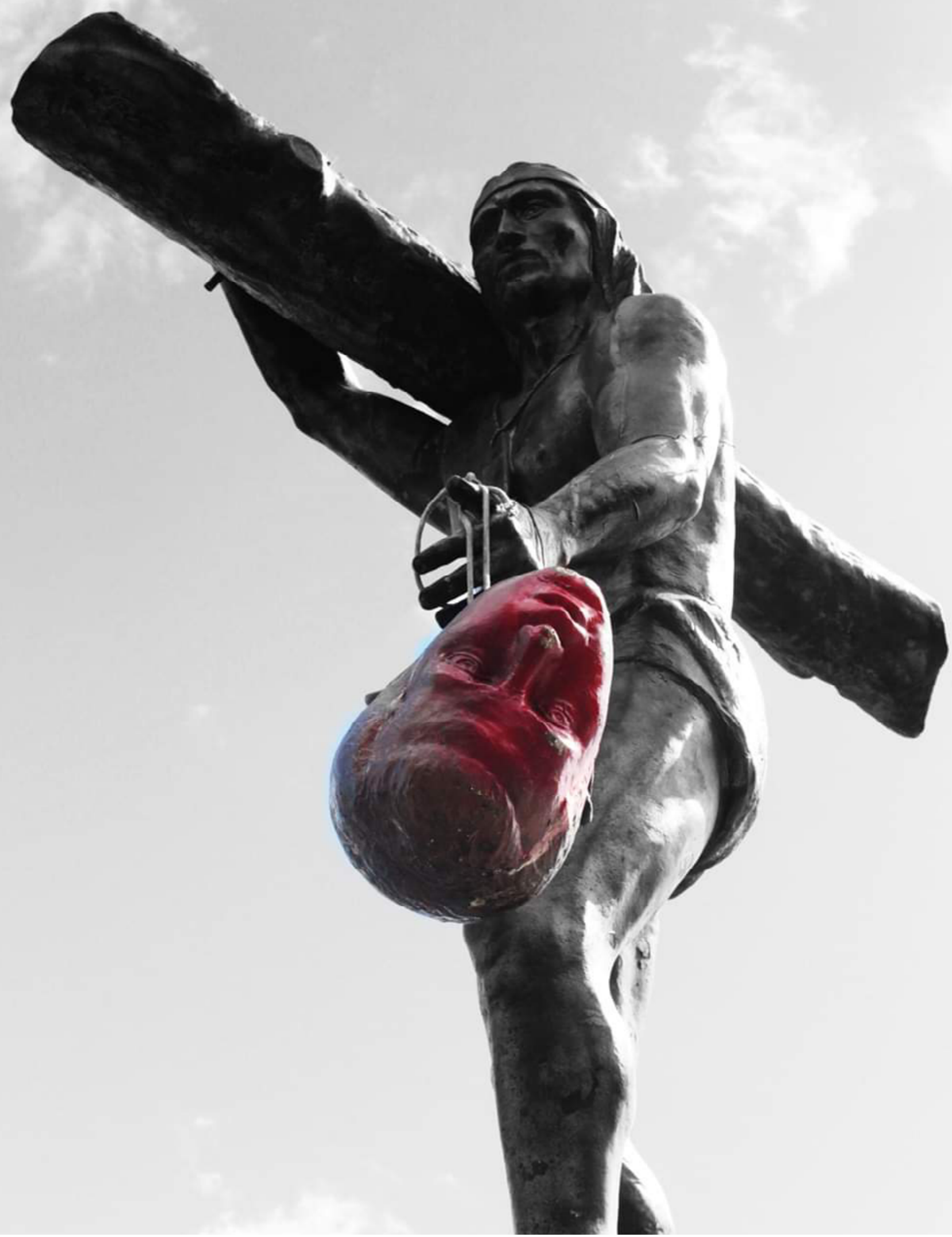

Figura 1. El 29 de octubre de 2019, en la ciudad de Temuco, los manifestantes decapitaron un busto de Pedro de Valdivia y pusieron su cabeza en las manos del monumento del toqui Caupolicán. (c) @araucaniaonline. 
primavera de 2019, poco se había dicho sobre este acápite del recetario prescrito por Milton Friedman. Dado que el sistema universitario tradicional estaba expuesto a la permanente contaminación ideológica de "células marxistas", urgía construir con celeridad "laboratorios" académicos en extremo inmunes. En perfecta asepsia, allí se desarrollarían las "medicinas" y los "placebos" que resguardarían la salud del cuerpo social que había salvado la cruel terapia del implacable Dr. Shock — piénsese, sin ir más lejos, en el Centro de Estudios Públicos (CEP) o en Libertad y Desarrollo (LyD), laboratorio "liberal" donde se adiestran los más influyentes asesores del presidente Sebastián Piñera-.

Precisamente, antes de la revolución, el capitalismo del desastre estimula la conformación e instalación de una casta de intelectuales ajena a un sistema universitario arruinado por las lógicas del mercado: abogados, economistas, filósofos, periodistas, politólogos, psicólogos y sociólogos cuyo prestigio obedece menos a la densidad de sus publicaciones académicas que a sus habilidades para construir discursos capaces de avalar la gestión de los decision makers del empresariado y el Estado. Con la irrupción de estos nuevos intelectuales, las humanidades comienzan a desfallecer ante las políticas públicas de pragmatismo neoliberal, y el ensayo y la crónica, siempre reflexivos, ante el paper y el editorial de impostura factual. Por lógica consecuencia, y en torpe afán de supervivencia, las universidades comienzan a adoptar los léxicos y los organigramas de las mismas corporaciones que las desdeñan. ${ }^{2}$ Las señales son claras: desde el final de la dictadura civil-militar,

capitalismo del desastre (The Shock Doctrine: The Rise of Disaster Capitalism [2007]), Naomi Klein diagnostica cómo Milton Friedman se unge como el médico de cabecera (el "doctor shock" [79]) que extirpa las patologías desarrollistas que —avivadas por Perón y Allende - habían conducido al Cono Sur, y a Chile en particular, al borde de la muerte. También sabemos que Klein documenta que Friedman - junto con Arnold Harberger - fue el mentor de una élite de jóvenes profesores de la Pontificia Universidad Católica de Chile que, desde las aulas, llegan a las oficinas del régimen dictatorial, en calidad de asesores clínicos, para implementar la terapia ideada por el propio Dr. Shock ("combatientes ideológicos" dispuestos a acabar con la peste roja [92]).

2 Una crítica afín ha sido formulada desde el contexto angloestadounidense, donde las universidades de élite ya se reconocen obsoletas: menos ágiles que las ONG y menos eficientes que los think tanks (Readings 17). Por defecto, varados como cetáceos prehistóricos en sus halls, los cuerpos de académicos asumen dos posiciones igualmente equívocas: "[c] 
los cinco presidentes de la Transición democrática han debido rendir sus exámenes de calificación en el auditorio del CEP, y no en las menguadas aulas de las universidades del Consejo de Rectores. Peor aún, estos intelectuales advenedizos son siempre los primeros en desdeñar, sin ambages, las jergas alambicadas y el fatalismo consuetudinario de las humanidades defenestradas. A ellos, que fruncen el ceño ante nuestras elucubraciones, Harold Bloom fallecido en la misma madrugada en que se comienza a fraguar la revuelta (14 oct. 2019) — les regaló el epíteto perfecto para motejar nuestros "sombríos" saberes: escuela del resentimiento (17).

Después de la revuelta, dichos intelectuales aún desfilan por paneles de expertos en políticas públicas alternando sus diagnósticos de ocasión con un consabido "nadie lo vio venir". Aunque, claro está, cuando pronuncian este mantra, olvidan que - tal como apunta Idelber Avelar - "lo intempestivo [que ninguno advirtió] es [precisamente] aquello que ha fracasado en la historia [tramada desde la doctrina del shock], pero sin cuya irrupción [próxima] ninguna historia [de la Transición] podría haberse constituido como tal" (212). ${ }^{3}$ Cuestión de perspectivas, reza mi tesis: para quienes nos desenvolvemos en facultades de humanidades — los territorios más diversos de la geografía universitaria tradicional-, el estallido social nos fue perpetuamente profetizado como filme, drama, novela, poema o performance. Para fundar este juicio, sirva un ejemplo personal, ya que hablo desde mi cotidianidad.

onservatives who seek to use the coercive and financial power of the State to correct what they see as ideological abuses within the professoriate are complicit in the destruction of the oldfashioned and timeless scholarship [. . . " y "[p]rogressives who want to turn the humanities into a laboratory for social change, a catalyst for cultural revolutions, a training camp for activists" (Stover par 5). Con ansiedad, ambas posiciones subyugan el quehacer universitario ante premisas que desvirtúan los regímenes que exige la docencia y la investigación no utilitaristas.

3 La mañana que siguió al estallido (20 oct.), el diario La Tercera publicó el especial "La crisis que nadie previó" (1-3). Cinco días después (25 oct.), CIPER, a través de una columna de Juan Carlos Castillo, comienza a interrogar la consigna. Afín a mi reconocimiento a las humanidades, Castillo advierte que, en ciencias sociales, hay colectivos de investigadores, ignorados por los decision makers, que "han dedicado años a estudiar distintos temas relacionados con nuestro malestar, como [. . . el el bajo monto de las pensiones, la colusión de algunos empresarios, la precariedad de la educación pública [o] la falta de justicia para los pueblos indígenas" (par. 1). 
Yo soy profesor de literatura dramática y, semestre a semestre, discuto con mis estudiantes - la mayoría, futuros profesores secundarios - un clásico del teatro chileno: Los invasores, de Egon Wolff (1926-2016), pieza en dos actos, estrenada bajo la dirección de Víctor Jara, por el Instituto de Teatro de la Universidad de Chile, en la sala Antonio Varas, el 19 de octubre, pero de 1963.

Recupero mis apuntes de clases - en absoluto originales - porque ellos muestran que esas demandas que tales intelectuales públicos no quisieron ver venir, en campus universitarios - y, también, en los establecimientos de educación secundaria donde se gesta la revuelta-, son las urgencias que animan nuestras conversaciones diarias. ${ }^{4}$ ¿Dónde están los petitorios de quienes vociferan disfrazados, desnudos o pancarta en mano?, ¿cuáles son las propuestas que parecen no poder escribir?, ¿en qué lengua habla la turba insurrecta? $\mathrm{O}$, de acuerdo con los tiempos, ¿cómo son esos invasores que comunicadores, estadistas, políticos y tecnócratas imaginan cubanos, rusos, venezolanos, incluso, alienígenas que arruinan la ciudad de los hombres y mujeres de "buena voluntad"? 5 : son estas las preguntas que, contra todo pragmatismo, las humanidades se vienen formulando hace ya buen rato.

4 Las ingentes movilizaciones sociales de octubre de 2019 comenzaron con centenares de estudiantes secundarios evadiendo el pago del tren subterráneo (Metro). Con ello, no solo protestaban contra un alza de 30 pesos en la tarifa del Metro (0.040 USD), sino contra un clima de abuso radicalizado por el ministro de Economía, quien, ante las críticas por el alza, señaló en entrevista con CNN Chile que "quien madrugue [y aproveche el horario valle] puede ser ayudado por una tarifa más baja" (05: 54). Por supuesto, esta protesta se entronca con una tradición política que reconoce a estos "actores secundarios" como una de las primeras avanzadas que siempre se articula ante situaciones de injusticia (e.g., la toma de liceo Alessandri en contra del procesos de municipalización/ destrucción de la educación pública [1985], el mochilazo en protesta por el alza de las tarifas escolares del trasporte público [2001] o revolución pingüina en rechazo a la desregulación del mercado de la educación [2006]). Diversas producciones culturales han reconocido el carácter de precursores de transformaciones sociales de este singular elenco (e.g., el documental Actores secundarios [2004], de Pachi Bustos y Jorge Leiva, o el texto dramático Liceo de niñas [2015], de Nona Fernández).

5 Aludo al vocativo usado por el presidente de la República, Sebastián Piñera, quien, en su alocución del 20 de octubre de 2019, señala que los manifestantes "están en guerra contra todos los chilenos de buena voluntad que queremos vivir en democracia con libertad y en paz" (par. 2). 


\section{EGON WOLFF, AUTOR DEL PRESENTE}

Ofrezco mis apuntes. Contextos, textos e intertextos suelen ser las secciones de una clase cualquiera. Sigo ese orden para dialogar con el presente. Ese lejano octubre del 63, desde donde enuncia el joven Wolff, estuvo signado por movimientos que favorecieron una revolución popular, como sabemos, por fuerza malograda (11 sep. 1973). Antes, entre el 27 de noviembre de 1962 y el 16 de julio de 1971 — la década de la emergencia de Los invasores-, el Estado de Chile promulgó, con inédito vigor, cuatro leyes que reconfiguraron, desde sus entrañas, el paisaje nacional. Me refiero a las leyes de reforma agraria (1962 y 1967), organizaciones comunitarias (1968) y nacionalización del cobre (1971). Entonces, el paisaje —esa trama de representaciones que organiza sistémicamente la geografía física y humana en que nos desenvolvemos (Cosgrove 65-66) - mutó de manera radical. Pero no solo en la particularidad de las parcelas normadas por las nuevas leyes (e.g., régimen de tierras, juntas de vecinos o recursos naturales), sino, también, en la amplitud del horizonte que limitaba el campo de lo posible: con la apertura de cada reducto, desde el subsuelo, brotaban preguntas, demandas y respuestas antes impensadas — por ello, "la insurrección de la burguesía", como mienta Patricio Guzmán-.

En tiempos en que nuestro quehacer universitario brega por ser encauzado a través de los rieles del mercado (repetimos con más ansiedad que fundamentos: economías creativas o innovación sostenible), es fascinante recordar cómo las artes escénicas de la "época 60" no cesaron en su afán por imaginar estos nuevos regímenes espaciales. Que lo digan los dramaturgos de esos teatros universitarios, los compañeros de Wolff. Más temprano que tarde, sus ficciones teatrales abonaron la tierra en que germinaron las mentadas leyes que acabaron por reinventar el paisaje. Alineadas con las movilizaciones de comunidades y pueblos que convergen bajo el alero de la nación, las dramaturgias de Isidora Aguirre, Alejandro Sieveking o el mismo Wolff, entre tantas otras, subieron a los escenarios a quienes no cabían en el paisaje de antaño - y que, por lo visto hoy en día, siguen "quedando en el camino"-: 
legiones de papeleros venidos de basurales y eriales (Los papeleros [1962], de Aguirre), ánimas de artesanas y campesinas sin lugar en un cielo figurado a medida de los "vivos" o "avivados" (Ánimas de día claro [1959], de Sieveking), además de nuestros invasores descalzos que marchan, pese a las amenazas policiales, desde el otro lado del río Mapocho. Para respaldar esta tesis, hemos explicado - en diversas instancias - que los teatros universitario de entonces: "must be considered genuine laboratories or factories where theatre students and scholars carefully crafted sophisticated embodied allegories of the country they dreamt about. The goal was at once to promote reforms and ideals among the people of all social spheres and start debates about them among the elites" (Grass, Kalawski, Opazo y Vergara, E-2).

Con todo, más allá de los epítetos, lo cierto es que estas dramaturgias enseñaron a sus audiencias formas subversivas para nombrar el paisaje. Con sus piruetas retóricas, los patipelados dividen, miden, reclaman, recortan o truecan la tierra con unidades que impugnan el código métrico del latifundio: "hay que borrar [d]e la tierra to[d]as estas cosas [cifras]" ya que "esta es mi tierra [por derecho ancestral] y aquí quiero trabajar" (Sieveking, Animas 64); por lo mismo, "[é]l dice que al otro lado del mundo, los campesinos ganaron la tierra, ¡haciendo la revolución!" (Aguirre, Los que van 11); total, qué más da si se cae en la lucha, si "aquí [en el fundo] uno se pudre... como agua en el fondo de una noria" (Heiremans, Abanderado 333). Aquí, las didascalias inscripciones de espacio y tiempo que saturan la escritura - son los cimientos que sostienen lugar de enunciación que la dramaturgia anhela erguir. Y, como bien avisaría Emile Benveniste, estos "indicies de ostentación" no solo describen la materialidad de dicho lugar, sino que, ante todo, representan el momento exacto en que el sujeto que enuncia se enfrenta a la lengua para encarnarla, desafiante, frente a los otros (84-85).

Desde esa coyuntura de reinvención del paisaje, en la que la dramaturgia esboza los primeros mapas del porvenir, Los invasores es un texto que, por la agudeza de su retórica, aún se lee como profético. Diez años antes del golpe, captura la enunciación perenne de las crispadas élites económicas que no soportaron el desorden que ya se gestaba, que por lo mismo hicieron sonar sus 
cacerolas exigiendo la intervención militar y que, más tarde, abrazaron con devoción las terapias del Dr. Shock: "[h]a habido tanto palabreo, últimamente, de la élite alborotada", "[d]ónde vamos a parar. . . . [s]i no paramos [nosotros] esas insolencias" (224), en fin, "[s]e hablaba, es cierto, pero era tan increíble que nadie perdía un minuto en pensar en ello" (249). ${ }^{6}$

Con estos antecedentes sobre la mesa, reparo en el texto mismo: en una casa cuyo living mira hacia las callampas del río Mapocho - camino "Insurgentes 241" (235)_, un industrial, que años antes cimentó su capital mediante una operación dolosa (Lucas Meyer), su esposa (Pietá) y sus dos hijos (Marcela y Bobby) resienten la invasión de una "manada de harapientos" (244) quienes, liderados por un tal China, vienen del otro lado del río - en su asalto, es verosímil oírlos vociferar las consignas que el pueblo chileno, en este instante, grita en la calle: "nos cansamos, nos unimos", "hasta que la dignidad sea costumbre". Enfrentada a las "fogatas" y al "desorden" con que se anuncian en las esquinas (243), Pietá y Marcela los perciben como "mugrientos" (237) y, ante todo, “monstruos" (¿alienígenas?) (243). Mientras tanto, Lucas - convencido de que la revuelta no es más que una serie de pasajeras "convulsiones del cuerpo social" que progresa (242) — intenta resolver la insurrección inventariando necesidades, ofreciendo limosnas. Para él, el dinero "[e]s arena" que "[s]e escurre por los bolsillos" y, así debe ser, porque esa arena es el mineral del que se alimenta una maquinaria de explotación cuyas bujías son "el gobierno, los impuestos, las instituciones de caridad" (234).

6 Literalmente, como precisa el texto, "se hablaba". Es un lugar común señalar que los Chicago Boys, epígonos criollos de Friedman, emergen recién en 1975. Y, peor aún, es una imperdonable desconocer que el convenio que vincula a las facultades de economía de las universidades Católica y de Chicago data de la década de 1950, que los primeros doctores chilenos de Chicago — contemporáneos a Wolff, y a Aguirre, Díaz, Heiremans y Vodanovicregresan a Chile a comienzos de los sesenta, que entonces golpean la puerta de La Moneda y que el presidente Jorge Alessandri, con astucia política, rechaza sus servicios. La lectura de Wolff ayuda a corregir este error y muestra cómo, en los días de Alessandri (1958-1964) o Frei (1964-1970), la "receta" neoliberal ya era un "antídoto" mencionado en las conversaciones de los Meyer y otras prósperas familias burguesas. 
Ante el anuncio de que "el señor Meyer. . . ha sido tan generoso de regalarnos cien mil pesos" (240), China y su hueste pasan de la irritación al desenfado. Con sorna, festinan el valor del dinero y se mofan de las operaciones omnívoras que en Chile este autoriza: no hay zonas vedadas - saben que es posible comprar, de manera indistinta, "una jaula de canarios", "un salchichón que llegue a la luna", "una camionada de mujeres" o un río de "paz" (241) - . Por lo mismo, desprecian el dinero. Se rehúsan a acuñarlo, al menos bajo reglas que ellos no discutieron. Más aún, impugnan la palabra del industrial que presume que la fórmula que paliará el descontento cabe, junto con la vida, en una calculadora: "¿sabes lo que este caballero tiene en la cabeza?” - se pregunta China-. "Una calculadora" — constata en el acto- (240). China, como sus herederos, declarará voz en cuello que no son treinta (ni cien) pesos, son treinta (y tantos más) años.

Así, pues, atenta a la enunciación de las élites, Wolff comprende, entre otros giros lingüísticos, la limitada noción de hospitalidad que manejan los Meyer. Para ellos, como para sus descendientes, hospitalidad supone autorizar el ingreso de los huéspedes a la lengua que previamente normaron, con ayuda de las calculadoras economicistas, los anfitriones: “i[q]ué harían ustedes si no tuvieran los nombres [calculados] para darle armado a todo esto" (239). Como bien repara China, esta es, ante todo, una relación asistencial y, por defecto, asimétrica. Las palabras (nos) hablan por si solas: "[f]ue absolutamente de mal gusto de parte de la Renée salir a bailar con el garzón, hoy, durante la fiesta, ¿no te parece? Se veía que lo hacía con repugnancia.. . Su condición de dueña de casa no la obligaba a ello, ¿no crees?" - lamenta Pietá al ver el trato que una vecina, Rennée Andreani, da a su servicio doméstico (225)—.

Consecuentemente, el exabrupto de Pietá conlleva un yerro semántico. Tal como precisaría J. Hillis Miller, Pietá olvida que los "dueños de casa" hospitalarios son aquellos que transforman su propio hogar en un espacio donde las reglas de convivencia se sustentan en un intercambio recíproco entre moradores y visitantes; durante el encuentro hospitalario, ambas partes comparten comidas y bebidas, pero también, procuran hallar una lengua común. Y, esta aseveración no es una mera hipérbole. Con el diccionario etimológico 
de la lengua inglesa sobre el escritorio, Hillis Miller parece recordarle a Pietá la lección de lenguaje que su clase suele desatender: "[t]he words host [anfitrión] and guest [huésped] go back in fact to the same etymological root: ghos-ti" (442). De ahí que para un anfitrión el huésped es "someone with whom one has reciprocal duties of hospitality", y viceversa (442).

\section{EL RETORNO DEL PUEBLO}

A partir de su ficción de 1963, Wolff nos advierte, hoy, que la (mala) suerte de los invasores no debe volver a ser reducida a cifras, guarismos, indicadores. Las asociaciones intertextuales se multiplican. Durante las manifestaciones de nuestra Revolución de Octubre, el discurso de la presidencia - y el de la derecha extrema que lo secunda desde Twitter con su ejército de bots - ha sido despojar de agencia al pueblo que rechaza las medidas brotadas con prisa desde las calculadoras del establishment político-empresarial. Digo pueblo — sustantivo común y colectivo - porque, en sus cánticos de rima futbolera, así se reclama, y ya no como la difusa ciudadanía del deslavado liberalismo económico —acumulación inorgánica de individualidades_- “el pueblo,/ el pueblo,/ ¿el pueblo dónde está?/ El pueblo está en la calle/ pidiendo dignidad". El reclamo no es trivial: en el teatro de la Transición — tan distinto a ese que formó a Wolff y sus compañeros_-, olvidamos demasiado rápido que el pueblo es el actor colectivo; la democracia, el escenario que favorece su protagonismo; y la ciudadanía, el papel que dicho actor debe interpretar de acuerdo con la planta de movimientos que direcciona su actuar.

Más aún, permítaseme ensayar una precisión adicional: pueblo, por un lado, designa a todos quienes potencialmente pertenecen al demos que produce las reglas de ciudadanía; pero, por otro, designa a ese elemento irreductible que las mismas reglas de ciudadanía declaran interdicto. Sebastián Barros observa que "[p]aradójicamente. . . todos los miembros del pueblo son y no son al mismo tiempo miembros del pueblo" (298). De manera consecuente, para mí, el pueblo es aquella colectividad que por fluctuante, móvil y vasta, nunca logra ser cabalmente direccionada por las reglas de ciudadanía; por lo 
mismo, los miembros remisos de este actor común son quienes hacen patente, por contraste, la vacuidad de la norma que intenta reducirlos.

Dicho esto, en el tinglado del presente, las precisiones léxicas apremian: cuando circulan en las redes sociales llamados a no manifestarse, que dicen representar a cinco millones de silentes chilenos más interesados en el orden y el progreso que en la "sucia política", numerosos líderes de partidos y de opinión infantilizan a ese actor colectivo. No serían - dicen ellos- más que pandillas de irracionales millennials prisioneros de sus pulsiones (Peña, "Malestar" D15). O, cuando no, esos mismos líderes a veces optan por "externalizar" la agencia popular: más de alguien ha anunciado una invasión de fuerzas externas a la puesta en escena democrática — aliens, por cierto, y no escuadrones policiales de uniformes igualmente verdes (BBC par. 2)-. Para estos políticos y opinólogos, "los chilenos de buena voluntad" - ¡cómo insisten en ese vocativo! - son los silentes trabajadores, actores secundarios que se sacrifican, como mártires de la doctrina del shock. Para quienes han venido reproduciendo este discurso - idéntico al de Pietá y Marcela—, todo el resto que sale a las calles no es más que un cúmulo de vándalos, marcianos o infiltrados del castro-chavismo internacional que, con un celular, pueden hacer caer las bolsas del mundo. No deja de asombrar que quienes dirigen el gran teatro de la nación (o aquellos que aspiran a hacerlo) dejen entrever que en su proyecto país —otro adefesio gramatical que se esparce sin hallar debida resistencia - hay tantos que no conseguirán papel alguno. Como la casa de los Meyer, el Chile que sueñan será solo con ellos y con los que por ellos se sacrificarán.

Con todo, para Wolff el peligro no se agota en los discursos de quienes, como Lucas, Pietá y Marcela, quieren a los harapientos reducidos al otro lado del Mapocho. A la inversa, el hijo mayor de Lucas, Bobby, es un universitario (¿quizá estudiante de ciencias sociales o humanidades?) que apoya las vindicaciones, aunque - al igual que muchos masters in public policies adscritos a think tanks "liberales"- "se mueve como iluminado" (246). Con decisión irreflexiva, Bobby proclama "el ocaso de la propiedad privada" (246), pero jamás cuestiona su concomitancia con el orden que dice 
impugnar, ni menos su papel en el nuevo orden. Nunca lo oímos dudar de sus propias palabras. Peor aún, sin variar un ápice su discurso, se arroga el derecho de traducir (aquí, sinónimo de reducir) las demandas de sus huéspedes: "dictadura del proletariado", "igualdad, libertad y fraternidad" — espeta en irritante loop - (246). De seguro, hoy diría sin culpas: "que mis privilegios sean tus derechos".

Eso sí, la ceguera del universitario puede ser la nuestra. Cuando los harapientos convierten el jardín de la casa de los Meyer en una plaza pública o en un campamento, Bobby —obnubilado con su propia jerga - improvisa un proscenio y comienza a declamar arengas y soluciones frente a ellos. De manera sintomática, en la escena siguiente, los vociferantes hastiados ya "le han amarrado. . . un cartel que oprime su pecho y que dice, garabateado con letras inciertas, palabras" (248). Cómo no: el joven Meyer todavía cree que la revuelta puede caber en un modelo de marchas (columnas humanas que avanzan en línea tras un líder carismático) y concentraciones (donde la muchedumbre oye a ese líder frente a un escenario); confía en que al final de esa marcha o en el cierre de esa concentración será él quien, autorizado por su linaje, promulgará la sentencia definitiva (limosna o paquete de medidas paliativas). He ahí su error: porque, tal como anuncia China, "[n]uestro plan es el futuro. . . Lo improvisaremos" en el caos que sobreviene al estallido (248).

Enfrentados a semejante estallido popular, nosotros —al igual que Bobby — no veremos ni monstruos ni alienígenas, a diferencia de Lucas, Pietá, Marcela o sus epígonos contemporáneos. No obstante, sí podemos errar como él al abocarnos a celebrar el color del estallido con la misma condescendencia de los espectadores pasivos de un festival de temporada — entre Primavera Fauna y Lollapalooza cada quien encontrará su ejemplo-. En cambio, si somos consecuentes con nuestro oficio, sabremos que en la investigación teatral importa menos el resultado final (la puesta en escena evaluada con más o menos estrellas por la crítica periodística) que las preguntas que surgen en el camino (proceso creativo). Pues bien, vistas así las cosas, no debemos olvidar ni por un segundo que cada bandera, capucha, corpóreo, desnudo, esténcil o pancarta agitado en la vía que reclamamos pública es el emblema de una 
comunidad que, ahogada y baleada, no claudica. La potencia de la fotografía sobrecogedora capturada en la plaza de la Dignidad (ex Italia) la tarde de la denominada marcha del millón radica, justamente, en la carne de quienes, antes de trepar el monumento del general Baquedano, caminaron desde Lo Hermida o las villas Francia, Frei o La Reina - tal como lo hizo las huestes de China, desde la Chimba hasta Insurgentes (Fig. 2)-.

Nótese el pueblo encaramado sobre el monumento y la wenufoye mapuche en la cúspide: antes del flash, la revuelta se coordina en anónimas organizaciones vecinales, trincheras donde aún se cultivan la memoria y los saberes de la protesta (Fig. 3): porque junto con la plástica multicolor superficie que encandilaría a Bobby_-, en pasajes laberínticos y multicanchas periféricas se aprenden las artes y oficios de la barricada, la batucada y el tinku, amén de las bondades del agua, el limón y la infalible cacerola, como primeras armas del derecho a rebelión. Porque, entre vecinos, todos juntos, también se ejercitan en la destreza coreográfica de hacerle verónicas a los perdigones y las lacrimógenas disparadas por las Fuerzas Especiales. Porque, desafiando las luces frías que iluminan las esquinas poblacionales, fueron ellos los que se armaron de valor - como tantas veces en nuestra historia- y cortaron el tránsito en avenida Grecia esquina Las Perdices, en la comuna de Peñalolén. Aún recuerdo: pancarta en mano, esa noche de septiembre de 2016, fueron ellos quienes nos avisaron, a pesar de los cercos comunicacionales, que "a la negra la mataron" por alzarse en contra del extractivismo corporativo (Reyes par. 1). En deber de memoria, urge reafirmar que son estas mismas células vecinales las que permiten recordar que aquello que para muchos de nosotros han sido semanas de inaceptables vulneraciones a los derechos humanos, en la población El Pinar o en la localidad de Temucuicui han sido inviernos del largo de la vida. 


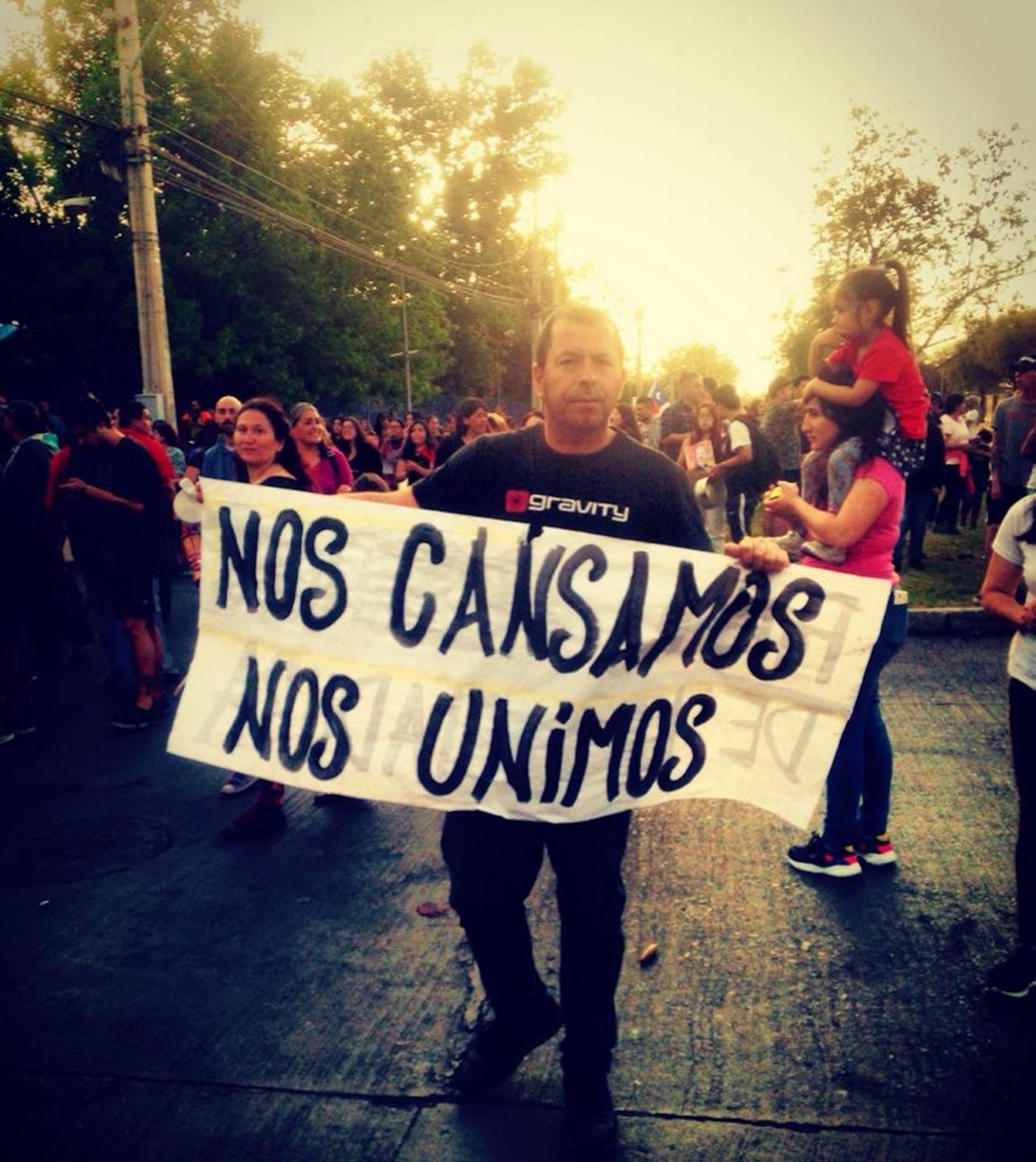

Figura 2. Monumento al General Baquedano, sector Plaza de la Dignidad, ex Italia, Santiago de Chile, durante la manifestación del 25 de octubre de 2019. (C) Susana Hidalgo,@su_hidalgo 


\section{TRIBUNAL DE LA DIGNIDAD}

Sobre el final del primer acto de Los invasores, lo que más inquieta a Pietá no es tanto la pérdida inminente de sus bienes como la desintegración de $s u$ cultura: "[t]e llevarán a vivir en barracones, abrazado de sacos con piojos. . . ¡Comerás en pailas grasientas! ¡Te volverán un bruto!” - le enrostra a su hijo (245) - La tenacidad de esta agencia popular que amenaza al sosiego de los Meyer y su descendencia es una verdad también palpable desde las salas de teatro locales. En el último lustro, buena parte de las piezas que con más crudeza rozan la nervadura de un Chile herido surgen, precisamente, de alianzas entre teatristas y "comunidades de base" que despliegan jergas que "mancillan", con el desparpajo de los invasores, nuestros lexicones estéticos. A su vez, dignos descendientes de los Meyer, numerosos críticos han reaccionado con escozor ante el teatro surgido de estas alianzas: como los industriales que denuncian el advenimiento de los populismos de izquierda, las voces críticas del presente temen el retorno del panfleto embrutecedor (De la Parra ctd. en Terra par. 2). En contra de este denuesto, me parece imperioso reparar en los modos de producción comunitarios de estos teatros "peligrosos" que, años antes de la llegada de nuestra última primavera, ya avisaban que Chile no era más que una zona de sacrificio, "areas that had undesirable characteristics", donde "people of color frequently liv[e]" (Lerner 9). O, traducido a nuestro presente, un enclave privatizado donde los derechos humanos son siempre violentados en nombre de un imperativo extractivista que mengua comunidades, democracias, ecosistemas, Estados y pueblos.

$\mathrm{Al}$ evocar estos teatros montados por dignos hijos expósitos de China y Toletole, pienso en tres montajes (teatrales, no de los otros) estrenados aquí en Santiago durante los últimos dos años y medio. Pienso en Mateluna (2017) de Guillermo Calderón y elenco que, en diálogo con el colectivo Libertad para Jorge Mateluna, exigió juicio imparcial para un exfrentista injustamente condenado a tres lustros de presidio en la cárcel de alta seguridad de la capital. Pienso, también, en Trewa (2019) de Paula González y KIMVN Teatro que, en colaboración con comunidades mapuche violentadas por el Estado de 
Chile, denunció el crimen de Macarena Valdés (la Negra), el cuasi homicidio de Brandon Hernández Huentecol y la represión que generan las Patrullas de Acercamiento a Comunidades Indígenas (PACI). Pienso, cómo no, en Irán \#3037 (2019) de Patricia Artés y Teatro Público que, en un esfuerzo de investigación conjunto con las mujeres sobrevivientes del centro de torturas conocido como Venda Sexy, buscó denunciar la violencia sexual ejercida por la Dirección Nacional de Inteligencia (DINA) contra militantes de izquierda - y que, con otros marcos institucionales, los informes emitidos por Amnesty International, Human Right Watch y la Organización de las Naciones Unidas acusan que continúan vigentes- $-{ }^{7} \mathrm{Y}$ podría pensar en tantos otros procesos creativos surgidos de la complicidad entre teatristas y comunidades en activa resistencia contra el dolor y el olvido (e.g., agrupaciones de sobrevivientes de abusos perpetrados por elEstado o por corporaciones transnacionales, colectivos LGTBI+ excluidos del orden civil o juntas de vecinos criminalizadas).

Efectivamente, Mateluna, Trewa o Irán \#3037, antes que documentales, fueron actos de urgencia fraguados en situaciones de apremio vital (e.g., encarcelamiento, homicidio e impunidad). Por lo mismo, en sus respectivos procesos creativos, sus directores o dramaturgos no salieron de la sala de ensayo para "secuestrar" - como dice una poética en boga - experiencias de otredad radical que sirvieran a la maquinaria del mentado teatro de lo real, cuya "vulgata", convertida en commodity por las industrias culturales, se termina vanagloriando de sus ejercicios de ventriloquía con cuerpos y voces segregadas

7 El 13 de diciembre de 2019, la Oficina del Alto Comisionado de Naciones Unidades para los Derechos Humanos (ACNUDH) publicó su Informe sobre la misión a Chile (30 de octubre-22 de noviembre de 2019). Sobre la base de 235 entrevistas, el documento sentencia que "existen razones fundadas para creer que, desde el 18 de octubre, se ha cometido un elevado número de violaciones a los derechos humanos", muchas de ellas perpetradas por medio de la "violencia sexual". Enseguida, especifica: "la ACNUDH ha recopilado información sobre 24 casos de violencia sexual contra mujeres (14), hombres (6), niñas adolescentes (3) y un adolescente [. . .]". Asimismo, "la ACNUDH observó que en todas las regiones visitadas, mujeres y adolescentes mujeres informaron que, durante la detención en comisarías, a menudo se las obligaba a desnudarse y hacer sentadillas". Por último, la ACNUDH consigna que el INDH ha oficiado "108 querellas por tortura" vinculadas "con alegaciones en 166 casos de violencia sexual [. . .]. Esto representa un aumento de cuatro veces en las demandas presentadas por tortura con violencia sexual en los últimos nueve años [. . .]" (18-19). 
(Tellas ctd. en Pauls 278). Muy por el contrario, los elencos encabezados por Calderón, González o Artés, “contaron lo que contaron” porque sus miembros fueron, antes que investigadores/creadores, "codeudores solidarios" de causas que defendieron en carne propia: en Mateluna, el elenco retribuye con un ejercicio orgullosamente panfletario el apoyo que el exfrentista le había entregado durante los ensayos de un montaje anterior, Escuela (2013); en Trewa, el colectivo trabaja con una comunidad mapuche que antes ya se había encontrado y reconocido en la ruka que cobijó su trabajo previo, Ñuke (2018); o incluso en Irán \#3037, la práctica escénica erguida a través de un lento trabajo etnográfico busca, como gesto de reparación para sus interlocutoras - jamás informantes—, tipificar un delito que la legislación chilena todavía calla, la violencia político-sexual como máquina de tortura.

Como los invasores que denuncian los crímenes sobre los que se yergue la fortuna de los Meyer, estos teatristas asaltan nuestras salas y denuncian que la mitad de ese Chile que se quiere en vías de desarrollo es, más bien, un territorio donde el extractivismo, con arsénico o plomo, suspende hasta el derecho a la vida misma. Y, como bien dicen, de acuerdo con el régimen de las zonas de sacrificio, urge liquidar, con igual rigor, a todos aquellos que entorpezcan la marcha de su maquinaria - llámense Jorge, Macarena y Brandon, o China y Toletole- Así, desde las tablas, este teatro acusa la corrupción y la debilidad de las instituciones democráticas. Parafraseando la definición de performance de Richard Schechner ("twice-behaved behavior" [36]), bien podría decirse que para los "cómplices" que convergen como creadores y espectadores en Mateluna, Trewa o Irán \#3037, el teatro todavía es una práctica que permite recuperar las conductas criminalizadas o proscritas de la democracia arrebatada que entrevimos con ingenua ilusión en esa década que medió entre la reforma agraria y la nacionalización del cobre, y la estocada militar del 73.

No solo eso. En los trabajos que reseño, el teatro emerge como una práctica que, antes que entretener, permite impugnar el cometido del poder judicial que reprime a estas comunidades signadas por la violencia: meticulosamente, cada uno de ellos enseña expedientes extraviados, expone leyes violadas, recoge testimonios censurados y reconstituye escenas de 
crímenes oscurecidos por los peritos de turno. Aquí la metáfora es ineludible: gracias a este trabajo de restitución, Mateluna, Trewa o Irán \#3037 convierten al teatro en un poder suplementario - "tribunal de la dignidad"- que esclarece homicidios y desbarata montajes en esas zonas de sacrificio donde los poderes del Estado parecen claudicar. Todavía más, los elencos encabezados por Calderón, González y Artés bien parecen enseñarnos una lección que no podemos desatender: en lugar de renunciar a sí mismos, e impostar el papel de activistas, los teatristas - $y$, por extensión, todos quienes ejercemos oficios próximos a las artes - tenemos la oportunidad de poner nuestros trabajos a disposición de la organización de militancias (colectivas, solidarias) que contribuyan a crear horizontes comunes para los activismos (aislados, perseguidos). ¿No es esta la forma en que Mateluna, Trewa o Irán \#3037 han contribuido a intersectar las demandas de esos actores desterrados hasta de los memoriales de nuestra frágil democracia? ¿Con sus trabajos reticentes a los provechos de las bellas artes, estos elencos no están acaso remedando el quehacer de esas hordas que, entrevistas por Wolff, confunden los límites entre estética y política?

\section{LA PREMIER DE LOS MEYER}

Vuelvo, pues, al texto de Wolff. Desde su estreno, Los invasores ha suscitado en críticos y espectadores el mismo temor que excitan las profecías. Esta lectura que nos aterra desde su premier tiene su germen en el texto mismo: tras el diálogo que inaugura el primer acto, Lucas permanece en aquel living "donde nada de lo que se ve ahí [es] barato" (221), y Pietá, aún turbada, se retira a su dormitorio. Todavía insomne, Lucas se encarga de apagar las luces y cerrar puertas y ventanas. Pero, de pronto, "[u]n golpe y cae un vidrio" (226). Del resto, ya sabemos: los harapientos "[e]staban en todas partes, rompiendo todo, llevándose todo" (262). En las últimas escenas, oímos la voz de Lucas: tras gritos de angustia, respira y avisa que el drama que hemos visto ha sido la representación de "[s]ueños, nada más", que "[y]a pasó todo" (263). Acto seguido, Lucas se incorpora al desayuno familiar, subraya la "lógica tan 
precisa" de su pesadilla que lo inquietó y acota que, en su fantasía, "el portero albino de la universidad" en la que estudia Bobby "quemaba [su] chamarra en una gran pira de fuego" (263). En las líneas finales, Bobby, que ha quedado lívido, retruca: "[e]so sucedió ayer" (263). Y la acotación sentencia: "[justo] cae un vidrio con gran estruendo" (263). Tal como el ventanal de la casa de camino Insurgentes 241, también puede caer la cuarta pared que blinda nuestro teatro de aquellos que queremos solo como personajes. Cae el telón, brotan los aplausos.

Ese temor, que sigue siendo atávico, pena nuestras salas. Especulo: en el texto de Wolff, la pesadilla de los Meyer se inicia tras asistir a un evento público. La acotación inicial así avisa: "llaves en la cerradura.... [e]ntran Lucas. ..y Pietá. ... [v]isten de etiqueta, con sobria elegancia" (221). En el centro del living, Pietá, "con los ojos al cielo", ríe mientras Lucas "la abraza por detrás" (222). De pronto, con la crispación de quien recobra la conciencian tras una sutil embriaguez, Pietá cabila: "[c]uando todo sale bien, me asusto" (222). A juzgar por el vestuario, Lucas y Pietá regresan de una gala: "etiqueta", "sobria elegancia" (221). Y, por época y hábitos probos, es verosímil suponerlos de vuelta de una cena de beneficencia o de alguna première de teatro universitario. Tal vez, esta antecedió a la otra. Especulemos. De seguro, en el foyer del Camilo Henríquez (TEUC) o del Antonio Varas (TEUCH), la pareja ejemplar participó del vino de honor y, con el decoro que exige la clase, evitó revelar la incomodidad que le había causado el texto apenas estrenado por una novel compañía. ¿Será que han visto Los papeleros (1962), de la joven Aguirre, la misma que los había encantado con La Pérgola de las Flores (1960)? De ahí, quizá, venía el miedo — como diría Jorge Marchant—. En cualquier caso, aquí, la ficción dramática adelanta el malestar de sus primeros espectadores.

Cerca de nuestro octubre, los descendientes de los Meyer, quizá, han tenido sus propias funciones de pesadilla. Los imagino asistiendo, por costumbre o error, a alguna función de Mateluna, Trewa o Irán \#3037. Tras la función, habrían querido cenar distendidos en algún bulevar contiguo, en la plaza Nuñoa o en el paseo Lastarria. Pero, esa noche, no lo consiguieron. De seguro, ellos aún tienen grabado en sus memorias el inquietante régimen de 
participación de los subversivos espectadores. Lo imagino así porque me consta: función tras función, la interlocución de los asistentes a Mateluna, Trewa o Irán \#3037 fue siempre directamente proporcional al trabajo comunitario que antecedió sus respectivas puestas en escena. Más allá del aplauso y el saludo multiplicado por tres, las arengas, las colectas, los conversatorios, los foros, las velatones y los vítores desgarrados se percibían como las primeras chispas de la explosión por venir. Recuerdo con particular nitidez los finales de las funciones de Trewa en el Teatro UC, en plena plaza Ñuñoa, en abril recién pasado: desde las graderías de la sala Eugenio Dittborn, brotaba el llanto, estallaban las trutrucas, emergía el afafán, flameaba la wenufoye $\mathrm{y}$, antes de bajar el telón, la misma Paula González, recordaba el correo electrónico de las redes de apoyo de los comuneros mapuche asesinados, masacrados, violentados que precisaban ayuda ya. ¿Qué habrán comentado lo nietos de los Meyer a la salida de la función? En el trayecto a casa, ¿se les habrá venido a la memoria el recuerdo incómodo - transmitido por sus padres y abuelos- de las células vecinales que, en dictadura, la terapia de shock del Dr. Friedman había prometido extirpar como si se tratara de elementos cancerígenos? O, insomnes en sus camas, ¿cuántas veces habrán creído oír piedrazos contra los cristales? Esa noche de premier, esos chilenos también despertaron, aunque con un ánimo muy otro.

\section{LA MEZQUINA LENGUA DE LOS MEYER}

Recapitulo el sencillo ejercicio que he llevado a cabo: he cotejado la fábula de los Meyer con el presente y, con ello, he comentado las acepciones equívocas que adquieren, en la enunciación de las élites económicas, las voces hospitalidad y pueblo. Sobre la base de este ejercicio, quisiera concluir que la mezquindad de la lengua de los Meyer obedece a que ella siempre se enuncia bajo el alero de un Estado-nación que ha favorecido que el imperativo de la inmunidad impida el encuentro de la comunidad.

Antes de ilustrar este corolario, conviene abrir un paréntesis y citar a Roberto Esposito, quien señala que, antes de cualquier definición, es urgente 
comprender la carga etimológica que llevan consigo las voces comunidad e inmunidad: en las lenguas romances, el sustantivo comunidad es indivisible de su revés complementario, inmunidad. Tanto comunidad como inmunidad poseen el mismo étimo: el latín munus, que designa un "deber" o una “obligación". Precedido del prefijo con ("unión”), el “deber" o la "obligación" se tornan recíprocos. A su vez, antecedido por el prefijo in ("sin"), literalmente, se niega la reciprocidad (Tres 8, 55-56). Con idéntica lógica, operan las instituciones que informan las culturas del cénit de la modernidad capitalista (el Estado y el mercado). Por un lado, tales instituciones producen "aparatos de inmunización" que prohíben el ingreso de cuerpos ajenos a la cultura que protegen. Y, por otro, estas mismas instituciones construyen rebuscadas representaciones de las comunidades que, por ley, deben ser relegadas al más afuera de los cercos inmunitarios ("Comunidad" 73-74). De manera paradójica, toda empresa inmunitaria depende de la "generación controlada" del revés del que abjura ("Comunidad" 74).

La glosa de Esposito permite explicar que, al haberse alfabetizado en un régimen de inmunidad, los Meyer tienden a compartir un mismo "trastorno" de lenguaje. Pese a sus diferencias, Bobby, Lucas y Pietá todo el tiempo profieren enunciados cuyo fin último es conseguir el repliegue de los harapientos que los interpelan:

MEYER. (Lentamente, midiendo las palabras). Ayer en la tarde estuvieron unas monjas de la Caridad en mi oficina y les hice un cheque por una suma desmesurada; por poco hipoteco la fábrica a su favor. . . Lo curioso es que ni siquiera abogaron mucho por mi ayuda.... [S]e plantaron frente a mí con las manos extendidas y les hice el cheque. . . como si estuviera previsto que no me iba a negar. Después se retiraron haciendo pequeñas reverencias....

PIETÁ. ¿Fue miedo lo que sentiste?

MEYER. ... En el fondo sentí que, si no lo hubiera hecho, esas monjas se hubieran puesto a llorar por mí.

PIETÁ. ¿Llorar por ti?

MEYER. Creo que quise evitarles ese trance. . . Penoso. Extraño. . . . (224)

En términos de distancia social, los exabruptos de Pietá, las ofertas de Lucas o las arengas de Bobby no aceptan más respuesta que la sumisión del otro - un agradecimiento lastimero, un halago de las bases o una reverencia 
servil-. Por lo mismo, cada vez que los Meyer perciben que la palabra que han proferido no funciona como un dique infranqueable, reaccionan con un gesto reflejo — como la firma automática de cheques-, o, peor todavía, comienzan a padecer angustia, espasmos corporales y mareos. Esta enunciación que oscila entre la verticalidad patronal y la contorsión nauseabunda es, a fin de cuentas, el dispositivo que permite la perpetuación, más allá de la Colonia en plena república-, de un indecible régimen de castas: un apartheid criollo, como sentencia el ensayista Óscar Contardo en su reciente Antes de que fuera octubre (10-11). Pues bien, cada vez que Los invasores de Egon Wolff retornan a la escena crítica, se triza el dispositivo enunciativo de las élites económicas. Y, cuando eso ocurre, para unos pocos, el ruido de la trizadura se confunde con el de una pedrada en el cristal de la propia ventana.

\section{CODA: ASAMBLEA}

La violenta represión policial que sucedió al estallido hizo riesgoso acceder a los campus universitarios chilenos. A causa de ella, el segundo semestre de 2019 concluyó de manera anticipada y, con él, el curso del que estos apuntes fueron parte. En ellos, sentenciaba que el reclamo de los patipelados no se acalla con limosnas (desechos, o, en el mejor de los casos, excedentes producidos por un sistema financiero ungido como dogma). Por el contrario, lo que los angurrientos sí exigen es que los Meyer manifiesten su voluntad para renunciar a las leyes que norman con eficiencia monetarista incluso la industria de la caridad (ya lo insinúa Bertolt Brecht: la relación entre diezmos y rebajas tributarias suele ser directamente proporcional [5-6]): "[a]hora, las palabras son inútiles porque [ya] sabemos todas las respuestas y todas las justificaciones" (256). De ahí que, en la dramaturgia de Wolff, sea esta exigencia de refundación de códigos, lingüísticos y monetarios, lo que suscita el pavor de los "hombres y mujeres de buena voluntad":

CHINA. (Sentándose cómodamente, ríe.) Usted me hace reír [Meyer]. . . “Acribillo la balazos. .." Es incurable. . ¿Cuántas de esas palabras caben en una cabeza como la suya. . .? Usted lo llama "crimen" y con eso la cosa ya tiene nombre y usted tiene 
de donde agarrarse. . ¿Ha pensado alguna vez que el crimen es una consecuencia, y que sin causa no tiene nombre? (239)

El texto es minucioso en sus precisiones y sabemos que, en su asalto, China procura que sus huestes no vulneren los cuerpos de los dueños de casa; y con consecuente severidad, sofoca todo conato de gresca porque "yo no quiero muertes" (251). El fin de su protesta no es aniquilar la vida de los burgueses, sino el "armado de nombres" que, a punta de letras y números, establece precios y sanciona delitos: ahora deberán vivir " $[\mathrm{u}]$ na vida lenta, larga y lúcida. . . Tan larga y lúcida como la han llevado [. . .], pero [justo] a la inversa. . . ¡Con todo el horror de la certeza de no poder saquear más!” (251-52).

¿No es este reclamo de una vida nueva una forma de enunciar la pulsión que activa los sistemas libidinales del carnaval y la quema que invisten el cuerpo de Chile? Al terminar esa clase que no fue, habría dicho a mis estudiantes que la de los invasores es también la demanda por una nueva constitución. He dicho: no soy constitucionalista, sino profesor de literatura dramática. No obstante, debo confesar que si hay algo me seduce del proceso de instalación de una asamblea constituyente, que revoque el texto legado por la dictadura (1980), es justamente la posibilidad de regenerar, a partir de esas células estudiantiles, obreras y vecinales motejadas como invasoras, ese tejido social desgarrado a sangre y fuego tras sus conatos de alzamiento. Esta es la demanda de los insurrectos del presente, la causa que ilusiona al pueblo que sale a la calle a participar en manifestaciones multitudinarias o en ingentes cabildos autoconvocados. Y ¿qué pasa si fallamos en el intento? - se preguntará más de algún descendiente de los Meyer-. Poco importa: "nuestro plan es el futuro" (248). Y, en ese futuro que "improvisaremos" (248), confío en que ese tejido regenerado aliviará nuestra caída, y lo hará de mejor manera que la actual institucionalidad en su intento de menguar la crisis.

Con atendible aprensión, algunos columnistas denuncian los peligros de fetichizar la promulgación de una nueva constitución: Carlos Peña —entre otros- avisa que una nueva carta magna no se traduciría en una solución real 
que amaine el malestar ("Debate" A2). Sin embargo, el fetichismo que veo no es otro que el del propio Peña: me parece que él fetichiza la dimensión práctica de la política —esa misma de las "soluciones reales" para "los problemas reales de la gente" que proclama, en 1999, Joaquín Lavín (el autor del panfleto neoliberal, Chile: revolución silenciosa [1988] que, como denunció Eugenio Tironi, se escribió sobre los silencios de una dictadura criminal [1988])—. Precisamente, lo que está en juego - y que Peña insiste en "querer no ver", como diría María José Contreras - es el tabú de la reivindicación de la dignidad de un pueblo que necesita saberse soberano de sus decisiones. En una frase: el revés de la denuncia del fetiche constitucional es el tabú de la soberanía popular, incontable e indecible en la sintaxis de las cifras y las palabras del mercado. Y, es esta la soberanía que exigen los invasores cuando extrañan el sentido de toda suntuosidad (como Totelole, la compañera de China, que “comienza a vagar por la habitación [matrimonial de los Meyer y], mirando arrobada los objetos [. . . ] los toca con la punta de los dedos y lanza pequeñas exclamaciones de estupor y encanto" [230]).

Ya lo decía Wolff: no es (solo) cuestión de dinero; tampoco de cifras: pesos, kilogramos o metros - como creen los descendientes de la casta de los Meyer- . No. Creo que esto tiene que ver, más bien, con lo que obsesionaba a los personajes de un dramaturgo venido de esas mismas organizaciones sindicales y vecinales aniquilada silenciosamente por la revolución de Lavín — descendiente aventajado de los Meyer-; invoco a Juan Radrigán Rojas. Tal como dice Emilio en la escena final de sus imprescindibles Hechos consumados (1981), "son muchas veces las que me han obligado a dar dos pasos, muchas veces que he tenío que decir sí, cuando quiero decir no; son muchas veces ya las que he tenío que elegir no ser ná. . . No, compadre: de aquí no me muevo" (62).

\section{REFERENCIAS}

Aguirre, Isidora. Los que van quedando en el camino. Mueller, 1970. 
Alto Comisionado de las Naciones Unidas para los Derechos Humanos (ACNUDH). Informe sobre la misión a Chile (30 de octubre-22 de noviembre de 2019). Naciones Unidas, 2019.

Avelar, Idelber. Alegorías de la derrota: la ficción postdictatorial y el trabajo del duelo. Cuarto Propio, 2000.

Barros, Sebastián. "Populismo, pueblo y liderazgo en América Latina". Colombia Internacional, $\mathrm{N}^{\mathrm{o}}$ 82, sep.-dic. 2014, 297-302.

Benveniste, Emile. "El aparato formal de la enunciación". Problemas de lingüistica general, vol. 2, traducido por Juan Almela, Siglo XXI, 2004, 82-91.

Bloom, Harold. El canon occidental. Traducido por Damián Alou, Anagrama, 2006.

Castillo, Juan Carlos. “¿Nadie lo vio venir?”. CIPER, 25 oct. 2019, https://bit. ly/3gngUod. 1 de diciembre de 2019.

Contardo, Óscar. Antes de que fuera octubre. Planeta, 2020.

Cosgrove, Denis E. Social Formation and Symbolic Landscape. The U of Wisconsin P, 1998.

Espósito, Roberto. Comunidad y violencia. Círculo de Bellas Artes, 2009. . Tres ensayos sobre una teoría im-política. Editado pot A. Zagari, B. Gercman y A. González, Del Signo, 2009.

Grass, Milena, Andrés Kalawski, Cristián Opazo y Alexei Vergara. "New Opportunities, New Challenges: Graduate Studies in the Context of a New Institutional Paradigm for the Arts and Sciences in Chile". Theatre Topics, vol. 29, Nº 2, jul. 2019, E1-E8.

Heiremans, Luis Alberto. El abanderado. Teatro completo, editado por Norma Alcamán. RIL, 2002, 327-56.

Hillis Miller, Joseph. "The Critic as Host". Critical Inquiri, vol. 3, no. 3, 1977, 439-447.

Klein, Naomi. La doctrina del shock: el auge del capitalismo del desastre. Traducido por Isabel Fuentes García, Albino Santos, Remedios Diéguez y Ana Caerols, Paidós, 2011.

Lerner, Steven. Sacrifice Zones: The Front Lines of Chemical Exposures in the 
United States. MIT Press, 2010.

Pauls, Alan. "Secuestrar la realidad: entrevista con Vivi Tellas". Biodrama: proyecto archivos, editado por Pamela Brownell y Paola Hernández, Universidad Nacional de Córdoba, 2017, 273-79.

Piñera, Sebastián. "Discurso". Prensa Presidencia, 20 oct. 2019, https://bit. 1y/39PB1sA. 1 de diciembre de 2019.

Radrigán, Juan. Hechos consumados. Hechos consumados/Diatriba de la empecinada, Lom, 2006, 5-57.

Readings, Bill. The University in Ruins. Harvard UP, 1997.

Reyes, Sebastián. "El caso de Macarena Valdés: homicidio o suicidio". The Clinic, 31 ene. 2019, https://bit.ly/2DvB3tB. 16 de noviembre de 2019.

Schechner, Richard. Between Theatre and Anthropology. Prologado por Victor Turner, U of Pennsylvania P, 1985.

Sieveking, Alejandro. Ánimas de día claro. Mapocho, no. 2, 1963, 40-66.

Stover, Justin. "There's no Case for the Humanities". Public Affairs, vol. 1, no. 4, invierno 2017, https://bit.ly/3hYTypr. 1 de diciembre de 2019.

Wolff, Egon. Los invasores. Teatro completo, Society of Spanish and SpanishAmerican Studies, 1990, 221-263.

\section{Prensa}

"La crisis que nadie previó". La Tercera, 20 oct. 2019, 1-3.

"Min. de Economía y nueva tarifa de Metro: 'quien madrugue puede ser ayudado a través de una tarifa más baja"”. Lo Dijeron en CNN, conducido por Matilde Burgos, CNN Chile, 7 oct. 2019, https://bit. ly/2Xieksg. 3 de diciembre de 2019.

Peña, Carlos. "El debate de estos días". El Mercurio, 1 nov. 2019, A2. ."El malestar en la cultura". El Mercurio, 20 oct. 2019, D 15.

"Protestas en Chile: la controversia después de que la primera dama Cecilia Morel comparase las manifestaciones con una "invasión alienígena". BBC News Mundo, 23 oct. 2013, https://bbc.in/39LjaTI. 1 de noviembre 2019. 